Abstracta Iranica Abstracta Iranica

Revue bibliographique pour le domaine irano-aryen

Volume 24 | 2003

Comptes rendus des publications de 2001

\title{
s.v. « Germany. ii. Archaeological Explorations and Excavations ». Eir X, 5, pp. 519-530.
}

\section{Rémy Boucharlat}

\section{(2) OpenEdition}

1 Journals

\section{Édition électronique}

URL : http://journals.openedition.org/abstractairanica/34169

DOI : 10.4000/abstractairanica.34169

ISSN : 1961-960X

Éditeur :

CNRS (UMR 7528 Mondes iraniens et indiens), Éditions de l'IFRI

\section{Édition imprimée}

Date de publication : 15 mai 2003

ISSN : 0240-8910

Référence électronique

Rémy Boucharlat, «S.V. « Germany. ii. Archaeological Explorations and Excavations ». Eir X, 5,

pp. 519-530. », Abstracta Iranica [En ligne], Volume 24 | 2003, document 9, mis en ligne le 05 janvier 2010, consulté le 25 septembre 2020. URL : http://journals.openedition.org/abstractairanica/34169 ; DOI : https://doi.org/10.4000/abstractairanica.34169

Ce document a été généré automatiquement le 25 septembre 2020.

Tous droits réservés 


\title{
s.v. « Germany. ii. Archaeological Explorations and Excavations ». Eir $\mathrm{X}, 5, \mathrm{pp} .519-530$.
}

\author{
Rémy Boucharlat
}

1 Cette entrée très riche souligne d'abord l'intérêt des descriptions de monuments iraniens par les voyageurs, parmi lesquels émergent J. A. von Mandelslo, A. Olearius, E. Kaempfer au $17^{\mathrm{e}} \mathrm{s}$. et $\mathrm{C}$. Niebuhr au $18^{\mathrm{e}} \mathrm{s}$. Les premières décennies du $20^{\mathrm{e}} \mathrm{s}$. sont dominées par l'immense figure polyvalente de E. Herzfeld. C'est seulement à partir de 1958 que des missions archéologiques commencent, d'abord à Takht-i Solaiman et Zendan-i Solaiman en Azerbaijan, puis Bisutun à partir de 1963, Bastam en 1969, Firuzabad en 1975. En revanche, les archéologues allemands ont déployé une très grande activité dans les « surveys » archéologiques, en Azerbaij an surtout, privilégiant la période urartéenne, mais aussi dans des voyages de reconnaissance et dans des monographies ou études d'ensemble de monuments visibles.

On relèvera les différences entre les activités des archéologues allemands et celles des Français, qui malheureusement sont incomplètement décrites dans l'EIr (s.v. «Délégations archéologiques françaises »), car limitées à une institution. Pour les premiers, peu de fouilles qui commencent assez tard, beaucoup de reconnaissances, nombreux travaux sur la période islamique, et participation régulière des épigraphistes: en résumé, une activité dans la tradition de E. Herzfeld et de l' Orientalistik germanique. Chez les seconds, plusieurs fouilles, dont certaines de longue durée (Suse), très peu de voyages d'études, et bien peu d'intérêt pour la période islamique. 
INDEX

Thèmes : 1.3. Ouvrages généraux, histoire de la discipline

\section{AUTEURS}

RÉMY BOUCHARLAT

CNRS - Lyon 